\title{
Low-Profile Repeater Antenna with Parasitic Elements for On-On-Off WBAN Applications
}

\author{
Do-Gu Kang, Jinpil Tak, and Jaehoon Choi \\ Department of Electronics and Communications Engineering, Hanyang University, 222 Wangsimni-ro, Seongdong-gu, \\ Seoul 133-791, Republic of Korea
}

Correspondence should be addressed to Jaehoon Choi; choijh@hanyang.ac.kr

Received 23 October 2015; Revised 28 December 2015; Accepted 11 January 2016

Academic Editor: Muhammad Ramlee Kamarudin

Copyright (C) 2016 Do-Gu Kang et al. This is an open access article distributed under the Creative Commons Attribution License, which permits unrestricted use, distribution, and reproduction in any medium, provided the original work is properly cited.

\begin{abstract}
A low-profile repeater antenna with parasitic elements for on-on-off WBAN applications is proposed. The proposed antenna consists of a planar inverted-F antenna (PIFA), two parasitic elements, and a ground plane with a slot. Due to the slot, the impedance matching of the resonance formed by the PIFA is improved, which makes the proposed antenna operate in the $5.8 \mathrm{GHz}$ industrial, scientific, and medical (ISM) band. To cover the $5.2 \mathrm{GHz}$ wireless local area network (WLAN) band, a dual resonance characteristic is realized by the slot and the two parasitic elements. The first coupling between the PIFA and the slot not only makes the slot operate as a resonator, but also forms secondary coupling between the slot and the two parasitic elements. The two parasitic elements operate as an additional resonator due to secondary coupling. The antenna has the enhanced near surface radiation in the $5.8 \mathrm{GHz}$ ISM band due to addition of the slot and radiation toward off-body direction in the $5.2 \mathrm{GHz}$ WLAN band. In order to evaluate antenna performance considering the human body effect, the antenna characteristics on a human equivalent phantom are analyzed.
\end{abstract}

\section{Introduction}

In recent years, wireless body area network (WBAN) systems, communication systems transmitting or receiving a considerable amount of information near the human body, have been studied for various applications including medical, healthcare, automotive, and military services [1-3]. The antenna for WBAN systems should meet specific requirements, such as low-profile, low specific absorption rate (SAR), and stable performance, because the WBAN devices including the antenna are placed around the human body [4]. By establishing the proper communication link among WBAN devices, the vital signs of patients can be observed and transmitted [5]. In order to monitor the health status of patients, it is necessary to ensure robust on-off body communication between the wearable device (on-body device) and the monitoring device (off-body device) [6]. To improve on-off body communication performance, an on-on-off body repeater antenna suitable for on-on body communication (on-body device to the repeater antenna) and on-off body communication (the repeater antenna to off-body device) is needed. For on-on body communication, the antenna should strongly radiate along the surface direction of the body like a vertical monopole, that is, the monopole mounted vertically with respect to the ground $[7,8]$. However, since a vertical monopole has the largest height, it is not appropriate for on-body applications. For on-off body communication, the maximum radiation of the antenna should be in the normal to the surface of the body [9]. To satisfy the previously mentioned features, low-profile repeater antennas for on-on body and on-off body communications are researched [1012]. These repeater antennas consist of two radiators and two substrates: a half-circular patch (on-on body) and a slot (onoff body) [10], a long stripline (on-on body) and a patch (on-off body) [11], and a circular patch (on-off body) and a T-shaped patch (on-off body) [12]. However, these repeater antennas have the largest height due to the two substrates, which is not suitable for on-body applications. To overcome this problem, the repeater antenna is designed using a single substrate in this paper.

A low-profile repeater antenna with parasitic elements for on-on-off WBAN applications is proposed in this paper. By adding a slot and two parasitic elements, the antenna has a wideband characteristic covering the $5.2 \mathrm{GHz}$ wireless 


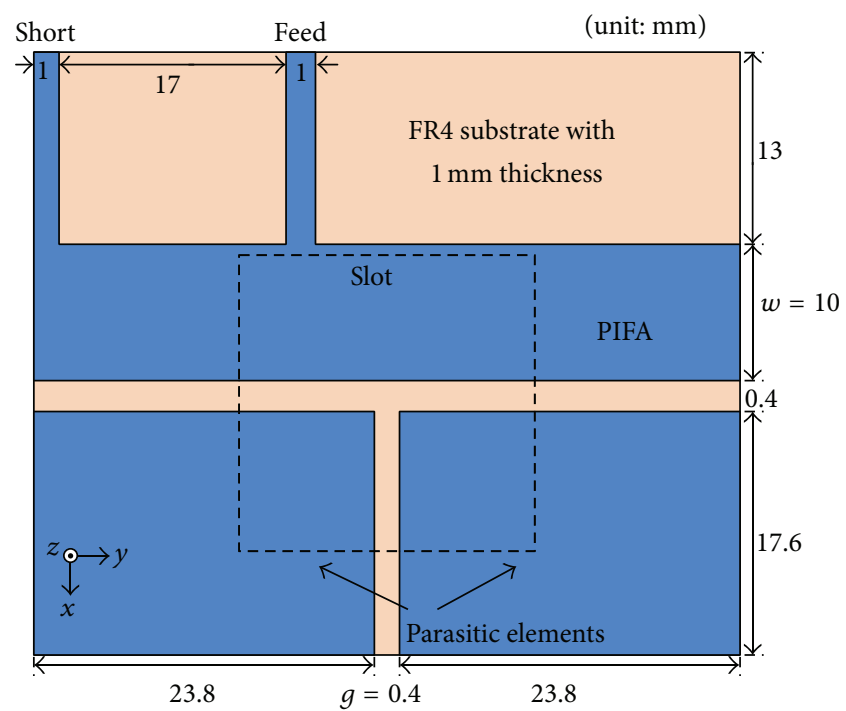

(a)

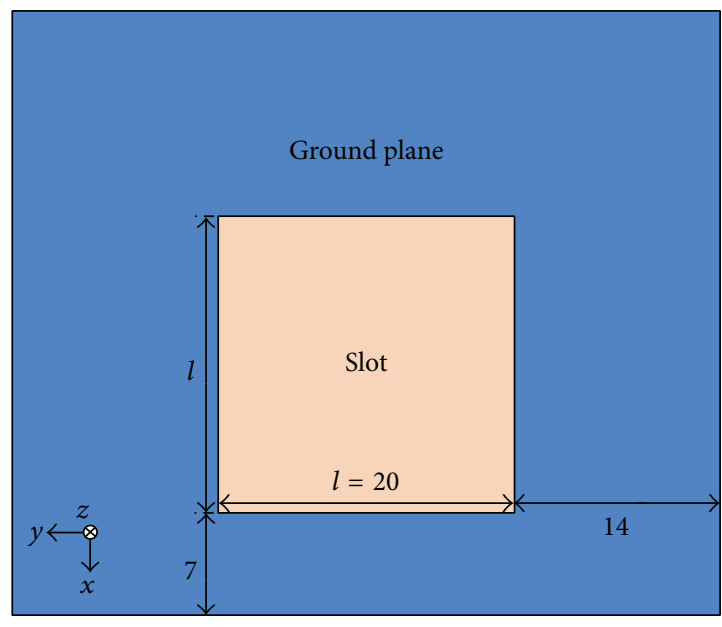

(b)

FIGURE 1: Configuration of the proposed antenna: (a) top view and (b) bottom view.

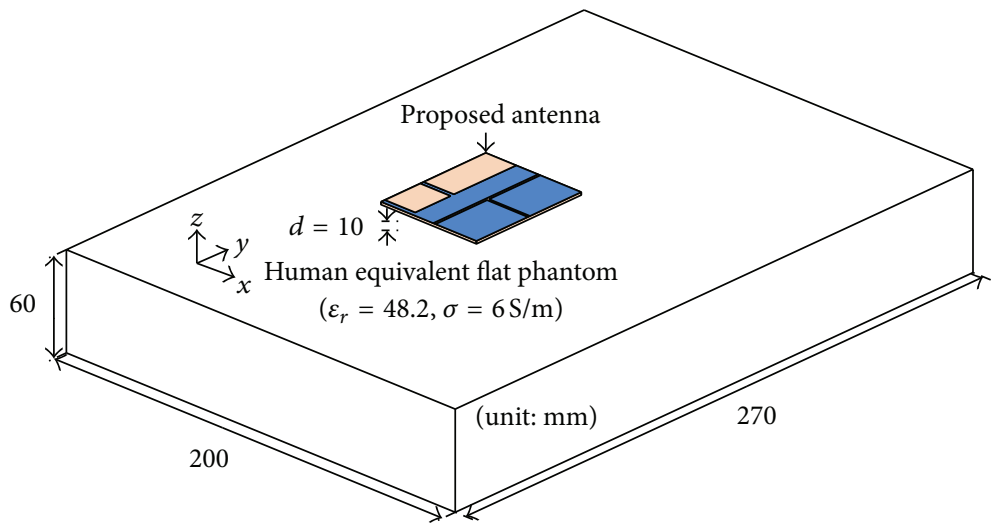

FIGURE 2: Simulation set-up of the proposed antenna on the phantom.

local area network (WLAN) band $(5.15 \mathrm{GHz}-5.35 \mathrm{GHz})$ and the $5.8 \mathrm{GHz}$ industrial, scientific, and medical (ISM) band which is defined as $5.725 \mathrm{GHz}-5.825 \mathrm{GHz}$ [13-15]. Due to the slot, near surface radiation is enhanced in the $5.8 \mathrm{GHz}$ ISM band for on-on body communication. In the $5.2 \mathrm{GHz}$ WLAN band, the antenna has on-off body radiation characteristics. The antenna performance is investigated by using a human equivalent phantom to include the effect of the human body.

\section{Antenna Configuration}

The proposed antenna consists of a PIFA, two parasitic elements, and a ground plane with a slot as shown in Figure 1. The PIFA with two parasitic elements is located on an FR4 substrate $\left(\varepsilon_{r}=4.4, \tan \delta=0.02\right)$. The dimension of the substrate is $41 \mathrm{~mm} \times 48 \mathrm{~mm} \times 1 \mathrm{~mm}$. The ground plane with the slot is placed on the bottom of the substrate. The slot is used to improve the impedance matching of the PIFA and operates as a resonator through the electromagnetic coupling between the PIFA and the slot. The two parasitic elements act as an additional resonator due to the secondary coupling between the slot and the two parasitic elements.

Figure 2 shows the simulation set-up of the proposed antenna on the phantom with a dimension of $200 \mathrm{~mm} \times$ $270 \mathrm{~mm} \times 60 \mathrm{~mm}$. The antenna and the phantom are separated by a distance of $10 \mathrm{~mm}$. To analyze the performance of the antenna on a human body, a phantom of human muscle tissue with electrical properties of $\varepsilon_{r}=48.2$ and $\sigma=6 \mathrm{~S} / \mathrm{m}$ is used [16].

\section{Operating Principle}

Figure 3 shows the simulated reflection coefficients of the proposed antenna in air and on the phantom and those of the antenna without the slot. The proposed antenna has three resonances and $\mathrm{a}-10 \mathrm{~dB}$ reflection coefficient bandwidth of 


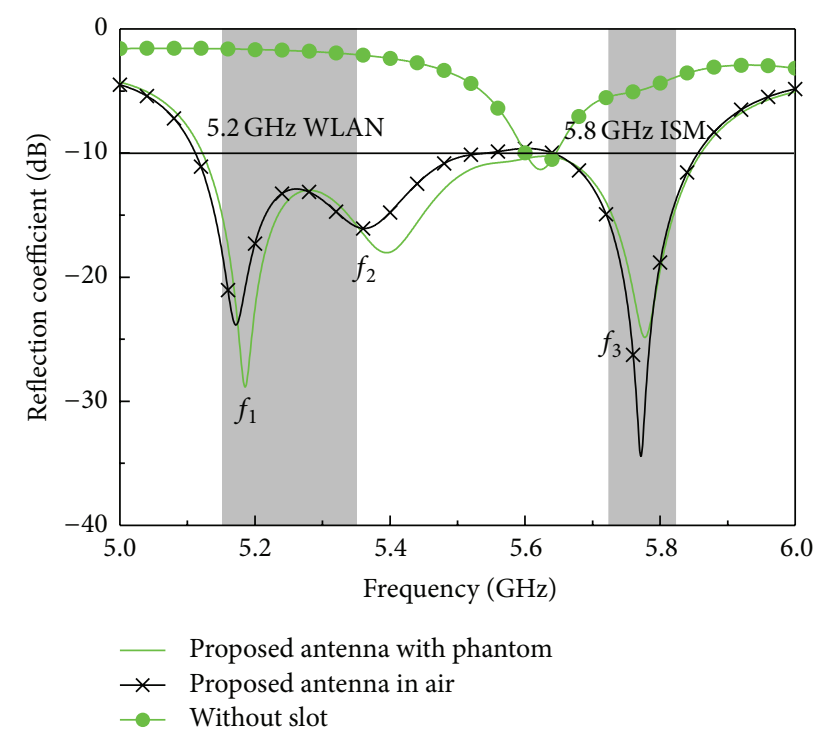

FIGURE 3: Simulated reflection coefficients of the proposed antenna in air and on the phantom and those of the antenna without a slot.

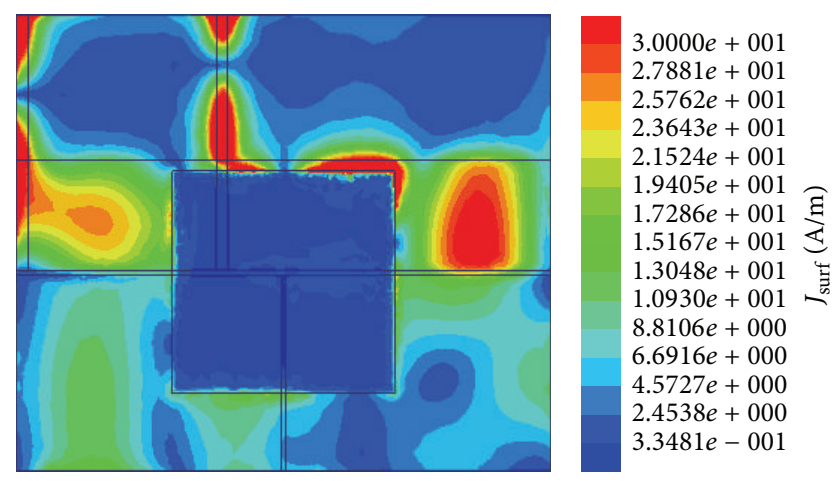

FigURE 4: Simulated surface current distribution on the ground plane of the proposed antenna at $5.77 \mathrm{GHz}$.

$0.74 \mathrm{GHz}(5.12 \mathrm{GHz}-5.86 \mathrm{GHz})$ covering the $5.2 \mathrm{GHz}$ WLAN band and the $5.8 \mathrm{GHz}$ ISM band. The resonance frequency of the antenna without the slot is due to the PIFA element and increases from $5.61 \mathrm{GHz}$ to $5.77 \mathrm{GHz}\left(f_{3}\right)$ with improved impedance matching by adding a slot. The reason why the resonance frequency increases due to the slot is because the coupling between the PIFA and the ground plane decreases due to a null field formed on the PIFA by the slot as shown in Figure 4, which decreases the equivalent electrical length of the PIFA. Eventually, the required bandwidth of the $5.8 \mathrm{GHz}$ ISM band is satisfied. The dual resonances $\left(f_{1}\right.$ and $f_{2}$ ) formed by the slot and two parasitic elements provide enough $-10 \mathrm{~dB}$ reflection coefficient bandwidth to cover the $5.2 \mathrm{GHz}$ WLAN band. When the reflection coefficients of the proposed antenna with and without the phantom are compared, it is observed that the antenna operates stably over the $5.2 \mathrm{GHz}$ WLAN band and the $5.8 \mathrm{GHz}$ ISM band, regardless of the existence of the phantom. The simulations are performed using HFSS [17].

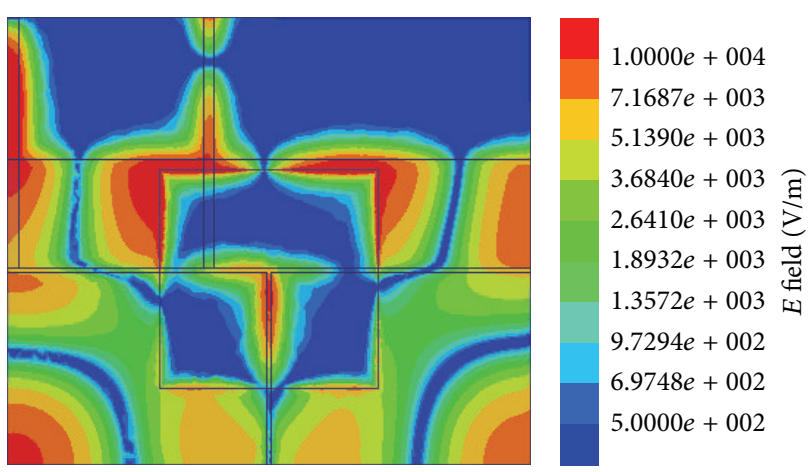

(a)

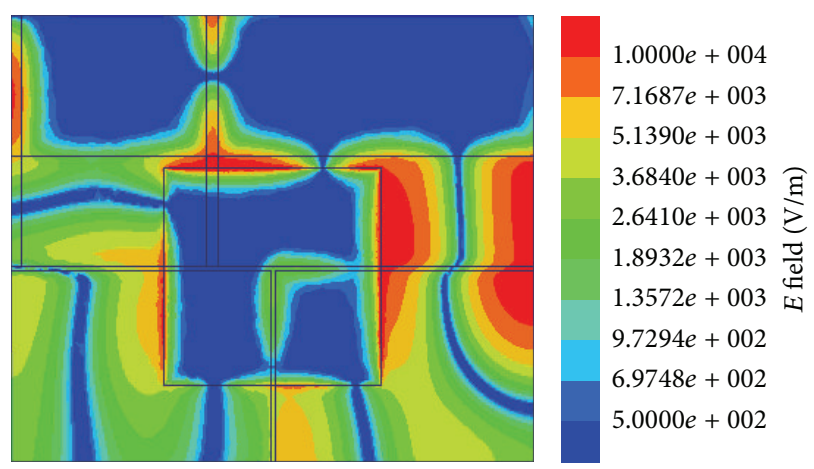

(b)

FIGURE 5: Simulated electric field distributions on the ground plane of the proposed antenna: (a) $5.18 \mathrm{GHz}$ and (b) $5.4 \mathrm{GHz}$.

Figures 4 and 5 illustrate the simulated surface current and electric field distributions of the proposed antenna, respectively. As shown in Figure 4, the PIFA mainly acts as a resonator at $f_{3}=5.77 \mathrm{GHz}$. In Figure 5, the first coupling between the PIFA and the slot not only makes the slot operate as a resonator at $f_{2}=5.4 \mathrm{GHz}$ but also generates the secondary coupling between the slot and the two parasitic elements. At $f_{1}=5.18 \mathrm{GHz}$, the two parasitic elements act as a resonator due to the secondary coupling.

\section{Parametric Analysis and Optimization}

Figure 6 illustrates the simulated reflection coefficients for various values of width $w$. As the width $w$ of the PIFA decreases slightly, the impedance matching of $f_{1}$ and $f_{2}$ deteriorates greatly. In contrast, $f_{3}$ formed by the PIFA remains relatively unchanged. The reason why the reduction of $w$ has an impact on $f_{1}$ and $f_{2}$ is that the electromagnetic coupling between the PIFA and the slot is affected substantially by the change in width of the PIFA. To achieve the wideband characteristic covering the $5.2 \mathrm{GHz}$ WLAN band and the $5.8 \mathrm{GHz}$ ISM band, $w$ is chosen to be $10 \mathrm{~mm}$.

In Figure 7, the simulated reflection coefficients for various values of gap distance $g$ are shown. As $g$ increases, $f_{1}$ increases with the degraded impedance matching, which confirms that the resonance at $f_{1}$ is formed by the two parasitic elements. Because $g$ is the gap distance between 


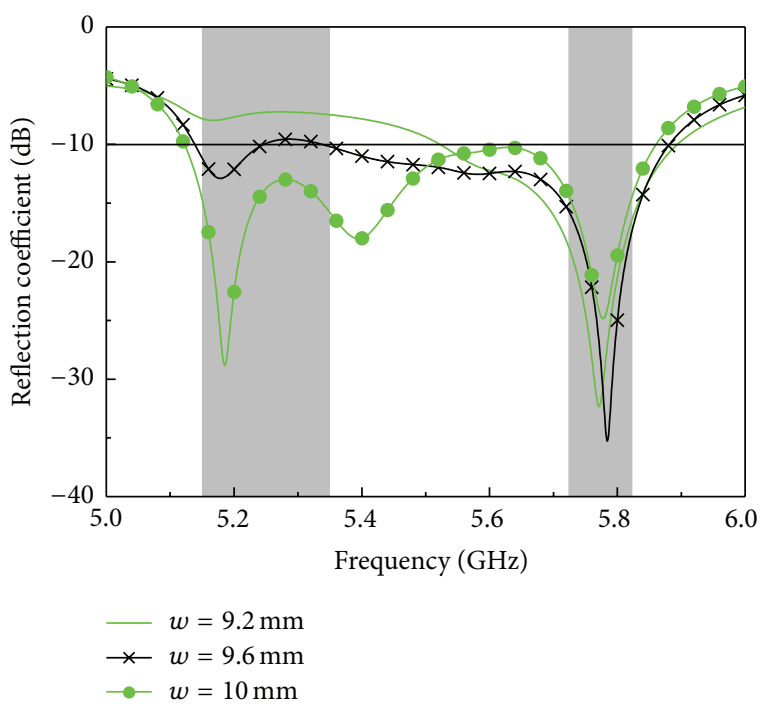

FIGURE 6: Simulated reflection coefficients for various values of width $w$.

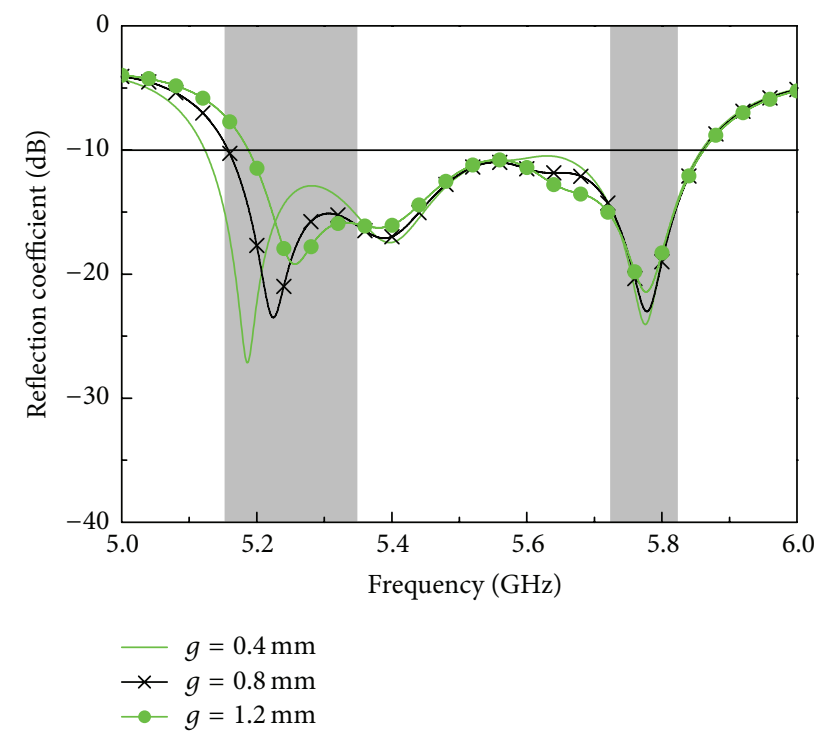

FIGURE 7: Simulated reflection coefficients for various values of gap distance $g$.

the two parasitic elements, the length of the two parasitic elements decreases by increasing $g$. In turn, the resonance frequency $f_{1}$ moves to the higher frequency side. By choosing $g=0.4 \mathrm{~mm}$, the proposed antenna simultaneously satisfies the $5.2 \mathrm{GHz}$ WLAN band and the $5.8 \mathrm{GHz}$ ISM band.

Figure 8 shows the simulated reflection coefficients for various values of length $l$. As $l$ decreases, the impedance matching at $f_{1}$ and $f_{3}$ deteriorates and the resonance frequency $f_{2}$ decreases. When $l$ is $20 \mathrm{~mm}$, the performance of the antenna is optimized to cover the $5.2 \mathrm{GHz}$ WLAN band and the $5.8 \mathrm{GHz}$ ISM band.

Figure 9 shows the simulated reflection coefficients for various values of distance $d$ between the antenna and

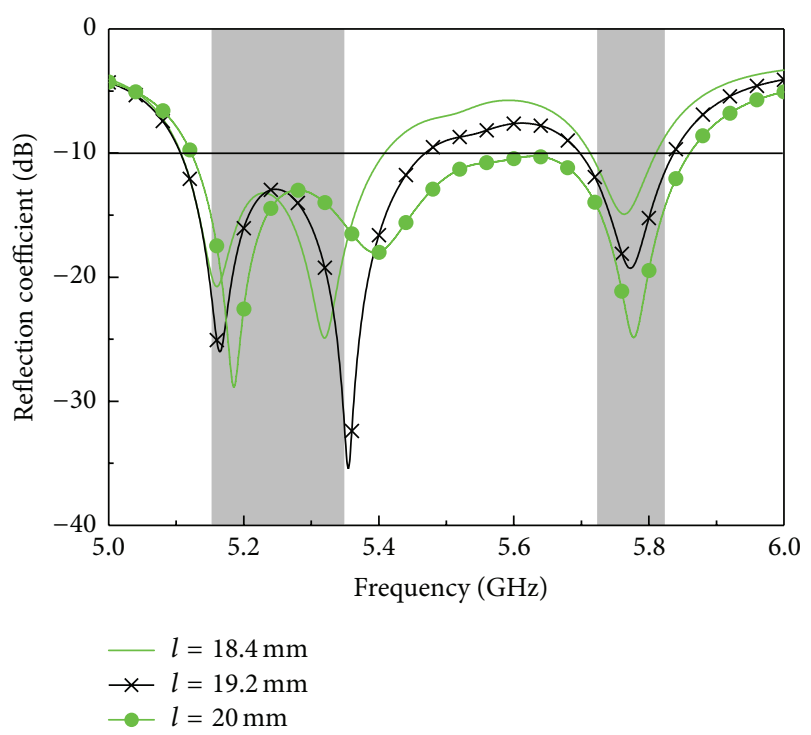

FIGURE 8: Simulated reflection coefficients for various values of length $l$.

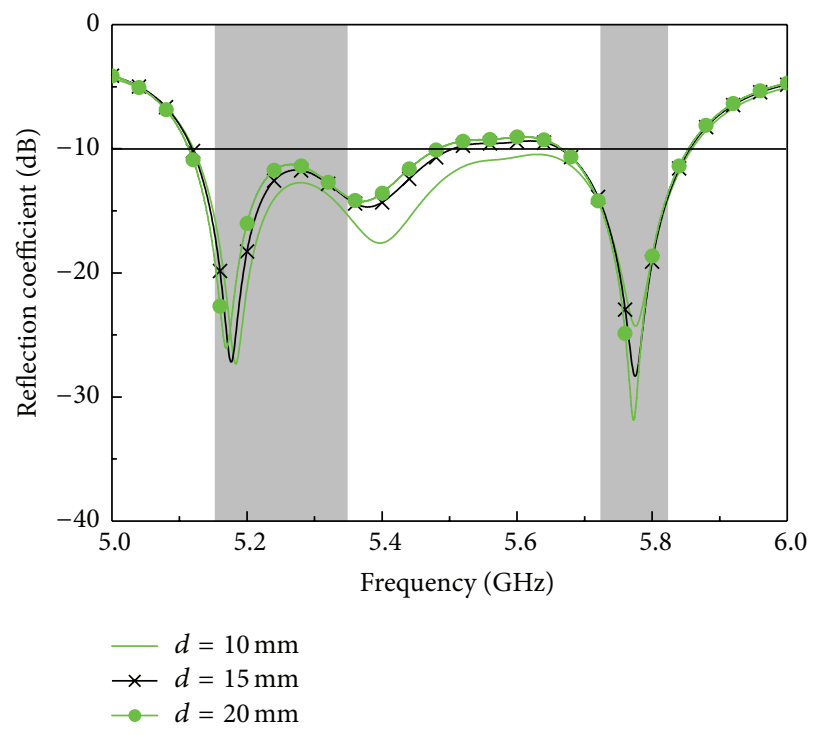

FIGURE 9: Simulated reflection coefficients for various values of distance $d$.

the phantom. As $d$ increases, the impedance matching of $f_{2}$ mainly deteriorates. When $d$ is $10 \mathrm{~mm}$, the wideband characteristic covering the $5.2 \mathrm{GHz}$ WLAN band and the $5.8 \mathrm{GHz}$ ISM band is achieved. Also, regardless of the change in $d$, the $-10 \mathrm{~dB}$ reflection coefficients bandwidth covers fully the $5.2 \mathrm{GHz}$ WLAN band and the $5.8 \mathrm{GHz}$ ISM band.

\section{Simulated and Measured Results}

In Figure 10, the manufactured prototype antenna is shown. In order to analyze the prototype antenna performance 


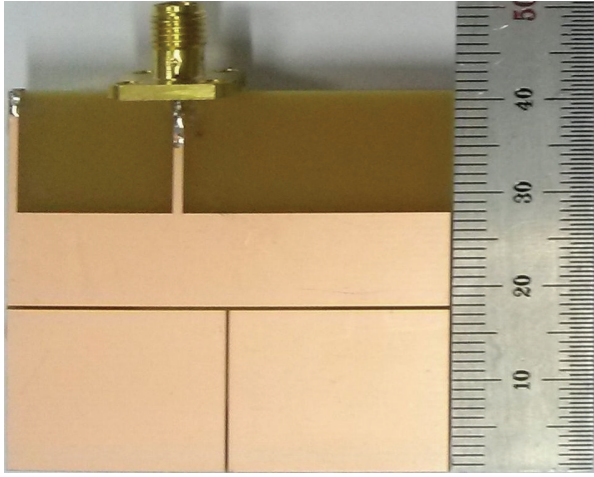

(a)

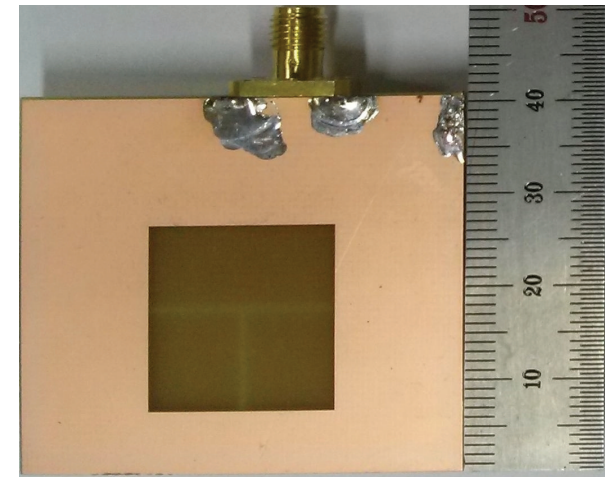

(b)

FIGURE 10: Manufactured prototype antenna: (a) top view and (b) bottom view.

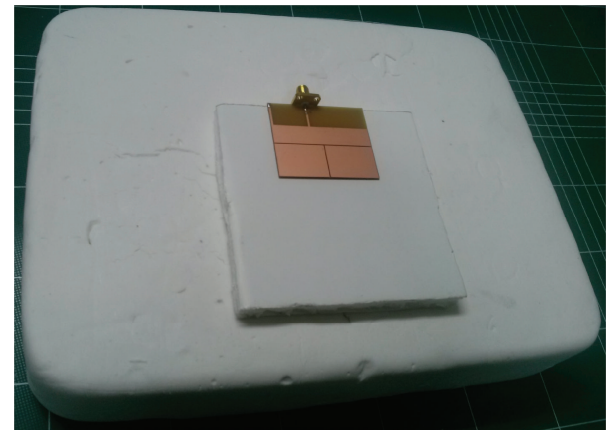

FIGURE 11: Measurement set-up of the prototype antenna on the manufactured phantom.

considering the human body effect, a manufactured human equivalent phantom [18] is used as shown in Figure 11.

Figure 12 illustrates the simulated and measured reflection coefficients of the proposed antenna. The simulated reflection coefficient is well matched with the measured one. The manufactured prototype antenna has a wide bandwidth $(5.1 \mathrm{GHz}-5.86 \mathrm{GHz})$ that can fully cover the $5.2 \mathrm{GHz}$ WLAN band and the $5.8 \mathrm{GHz}$ ISM band.

Figure 13 shows the simulated and measured radiation patterns of the proposed antenna. The simulated radiation patterns agree well with the measured ones. At $5.18 \mathrm{GHz}$, the antenna mainly radiates towards the direction which is normal to the phantom surface for on-off body communication. Because the antenna has maximum radiations along the $\theta=30^{\circ}$ direction in the $x z$-plane and the $\theta=45^{\circ}$ and $330^{\circ}$ directions in the $y z$-plane at $5.77 \mathrm{GHz}$, the proposed antenna is suitable for on-on body communication in the $5.8 \mathrm{GHz}$ ISM band. Therefore, the radiation characteristics of the proposed antenna are suitable for on-on-off WBAN repeater application. According to [19], the PIFA generally has maximum radiation towards the direction normal to the PIFA surface, whereas the proposed antenna has maximum radiation towards the surface due to the slot in the ground plane. The measured peak gains are $1.2 \mathrm{dBi}$ and $1.91 \mathrm{dBi}$ at $5.18 \mathrm{GHz}$ and $5.77 \mathrm{GHz}$, respectively.

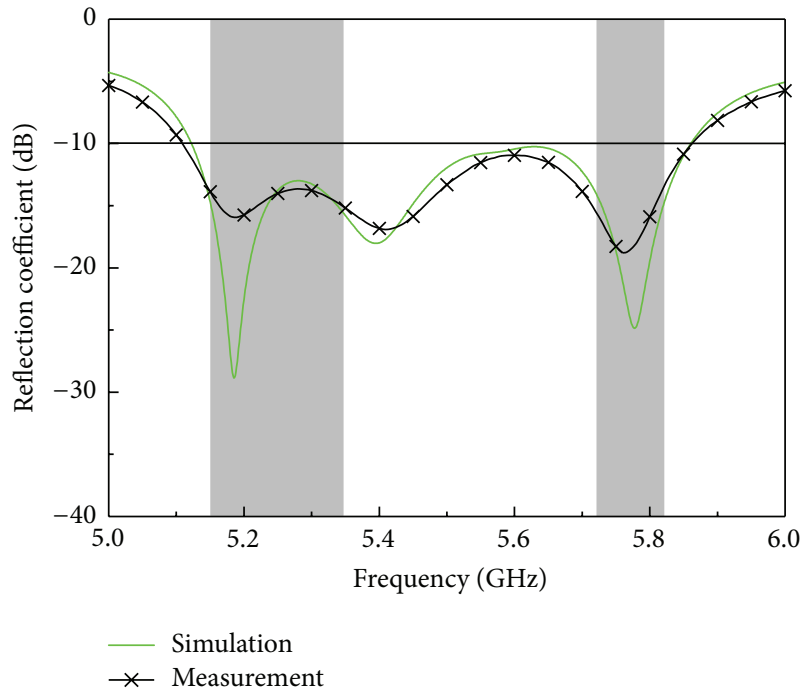

FIgURE 12: Simulated and measured reflection coefficients of the proposed antenna.

Figure 14 shows the simulated average SAR distributions of the proposed antenna when it is placed on the human equivalent phantom. The SAR value should be lower than $1.6 \mathrm{~W} / \mathrm{Kg}$ over a $1 \mathrm{~g}$ volume of tissue in a partial body [20]. When the input power of $65 \mathrm{~mW}$ is applied, the average SAR values are $0.55 \mathrm{~W} / \mathrm{kg}$ at $5.18 \mathrm{GHz}$ and $0.25 \mathrm{~W} / \mathrm{kg}$ at $5.77 \mathrm{GHz}$.

Figure 15 illustrates the simulation set-up of the onbody to on-body communication link. The two proposed antennas are placed on the human equivalent flat phantom with a dimension of $200 \mathrm{~mm} \times 800 \mathrm{~mm} \times 60 \mathrm{~mm}$. A distance between two proposed antennas is $500 \mathrm{~mm}$. Figure 16 illustrates the simulated $S$-parameters of the on-body to on-body communication link. The simulated peak $S_{21}$ value is $-55.6 \mathrm{~dB}$ at $5.77 \mathrm{GHz}$, which is suitable for the on-body to on-body communication link, described in [21].

In Table 1, the size comparison between previous repeater antennas and the proposed antenna is given. The proposed 


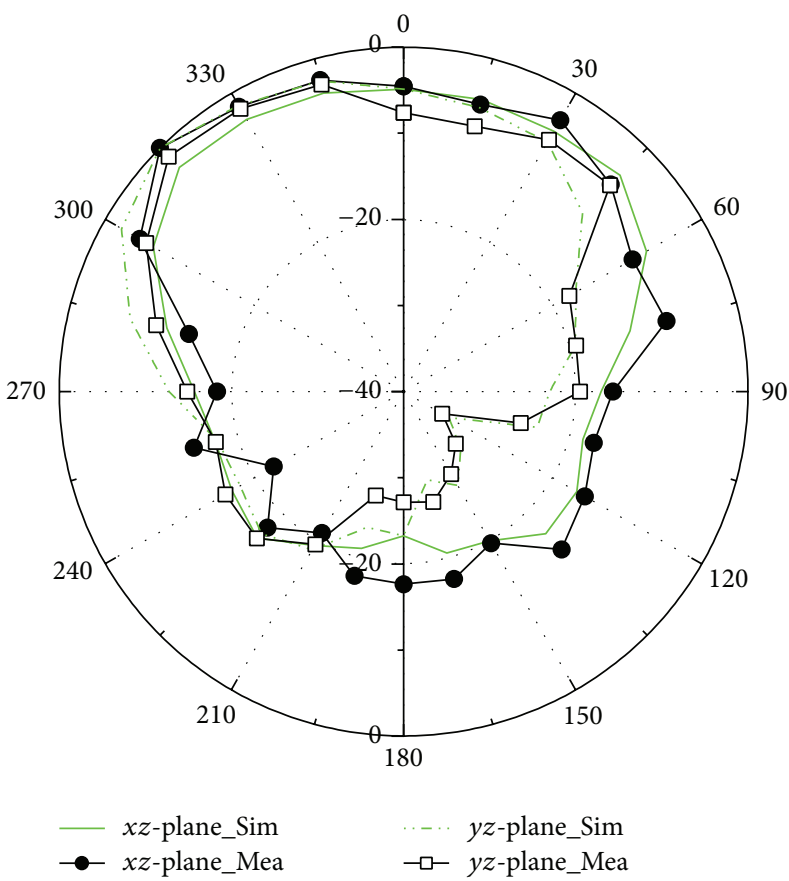

(a)

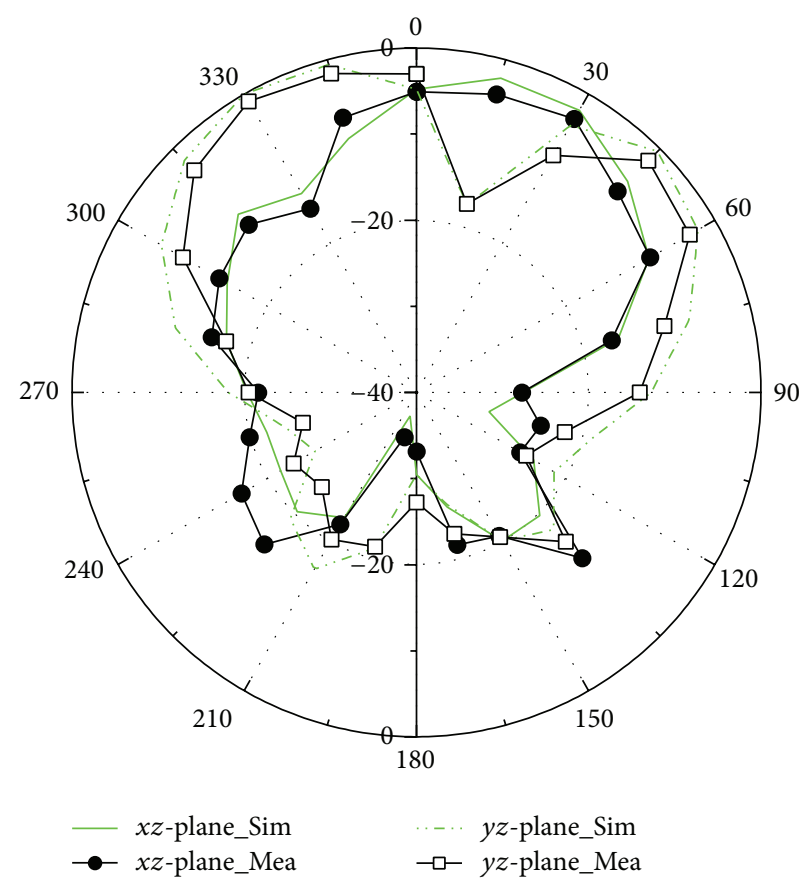

(b)

FIGURE 13: Simulated and measured radiation patterns of the proposed antenna: (a) $5.18 \mathrm{GHz}$ and (b) $5.77 \mathrm{GHz}$.

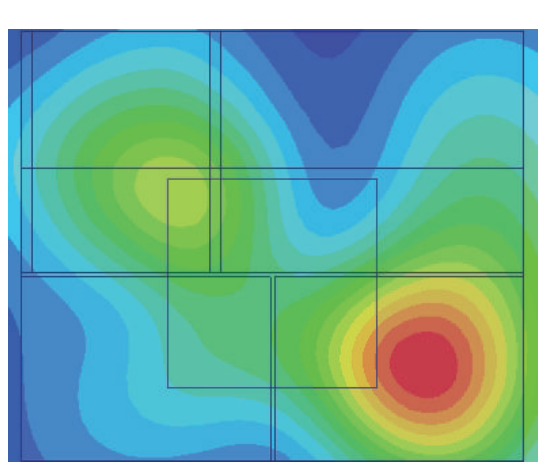

(a)

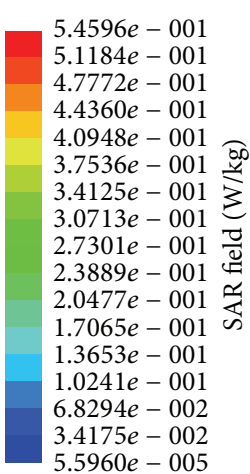

$5.5960 e-005$
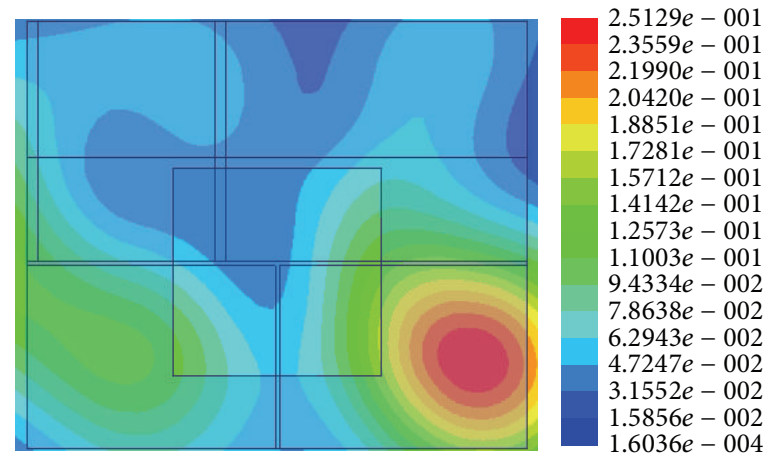

(b)

FIGURE 14: Simulated average SAR distributions of the proposed antenna when placed on the human equivalent phantom (input power: $65 \mathrm{~mW}$ ): (a) $5.18 \mathrm{GHz}$ and (b) $5.77 \mathrm{GHz}$.

TABLE 1: Size comparison between previous repeater antennas and proposed antenna.

\begin{tabular}{lcc}
\hline $\begin{array}{l}\text { Previous } \\
\text { works }\end{array}$ & $\begin{array}{c}\text { Volume } \\
\text { occupation }\end{array}$ & Thickness \\
\hline$[10]$ & $5956.6 \mathrm{~mm}^{3}$ & $3.15 \mathrm{~mm}\left(0.026 \lambda_{0} @ 2.45 \mathrm{GHz}\right)$ \\
{$[11]$} & $148500 \mathrm{~mm}^{3}$ & $5.5 \mathrm{~mm}\left(0.045 \lambda_{0} @ 2.45 \mathrm{GHz}\right)$ \\
{$[12]$} & $4320 \mathrm{~mm}^{3}$ & $3.2 \mathrm{~mm}\left(0.026 \lambda_{0} @ 2.4 \mathrm{GHz}\right)$ \\
$\begin{array}{l}\text { Proposed } \\
\text { antenna }\end{array}$ & $1968 \mathrm{~mm}^{3}$ & $1 \mathrm{~mm}\left(0.017 \lambda_{0} @ 5.18 \mathrm{GHz}\right)$ \\
\hline
\end{tabular}

antenna not only has the thinnest thickness but also occupies the smallest volume among the four repeater antennas in the comparison. Therefore, the proposed antenna is suitable as a low-profile on-body repeater antenna.

\section{Conclusion}

A low-profile PIFA antenna with parasitic elements for onon-off WBAN repeater applications is proposed in this paper. By using the slot and the parasitic elements, the antenna on the phantom has a wide $-10 \mathrm{~dB}$ reflection coefficient bandwidth of $0.76 \mathrm{GHz}$ covering the $5.2 \mathrm{GHz}$ WLAN band and the $5.8 \mathrm{GHz}$ ISM band. The near surface radiation of the antenna is enhanced by the slot for the $5.8 \mathrm{GHz}$ ISM band on-on body communication. In addition, the antenna mainly radiates towards the direction normal to the phantom surface 


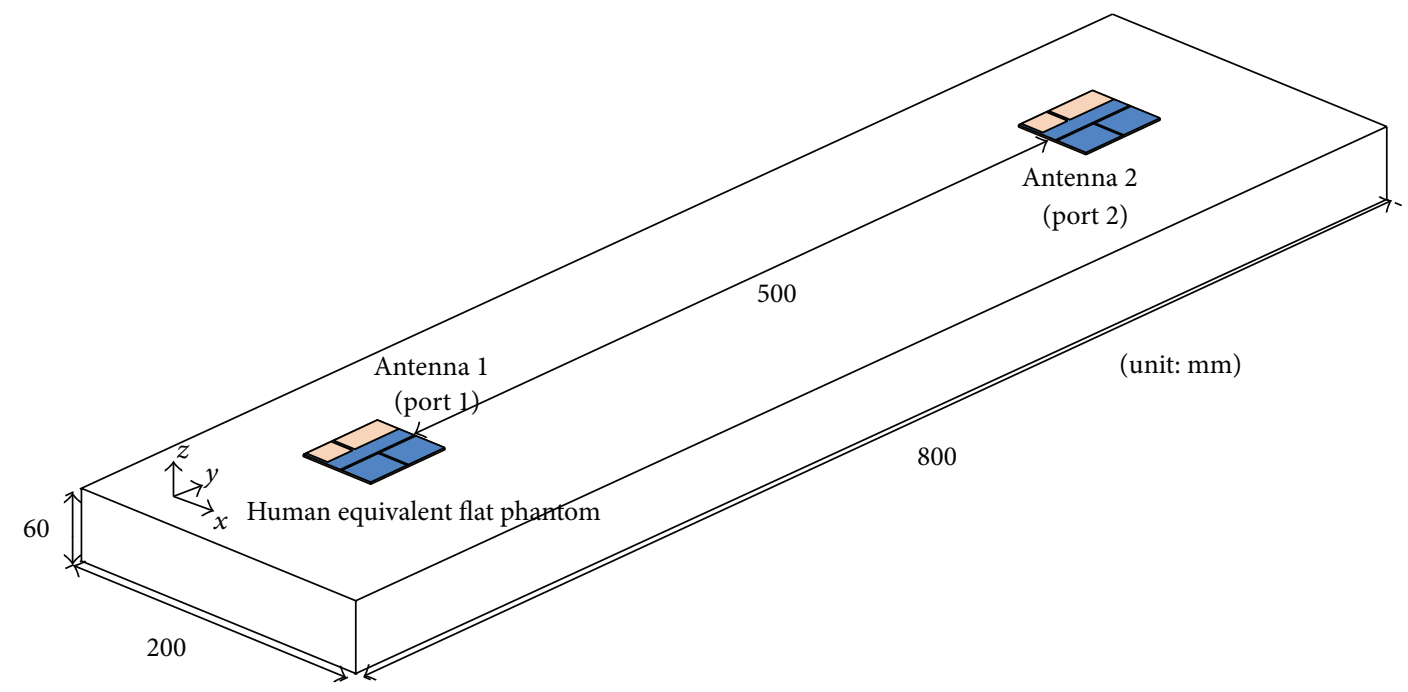

Figure 15: Simulation set-up of the on-body to on-body communication link.

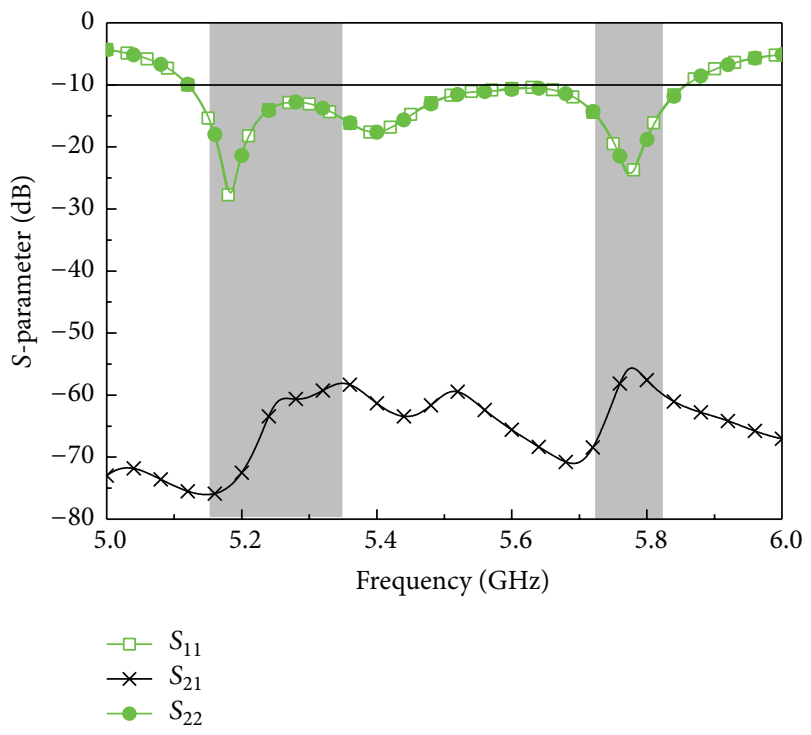

FIGURE 16: Simulated $S$-parameters of the on-body to on-body communication link.

at the $5.2 \mathrm{GHz}$ WLAN band. Consequently, the proposed antenna is a promising candidate for on-on-off WBAN applications.

\section{Conflict of Interests}

The authors declare that there is no conflict of interests regarding the publication of this paper.

\section{Acknowledgments}

This research was supported by the Korea Ministry of Land, Infrastructure, and Transport. It was also supported by the
Korea Agency for Infrastructure Technology Advancement (Project no. 15PTSI-C054118-07).

\section{References}

[1] T. Zasowski, F. Althaus, M. Stager, A. Wittneben, and G. Troster, "UWB for noninvasive wireless body area networks: channel measurements and results," in Proceedings of the IEEE Conference on Ultra Wideband Systems and Technologies (UWBST '03), pp. 285-289, IEEE, November 2003.

[2] P. S. Hall and Y. Hao, Antennas and Propagation for BodyCentric Wireless Communications, Artech House, Norwood, Mass, USA, 2006.

[3] S. Kim, K. Kwon, and J. Choi, "Design of a miniaturized highisolation diversity antenna for wearable WBAN applications," Journal of Electromagnetic Engineering and Science, vol. 13, no. 1, pp. 28-33, 2013.

[4] N. Haga, K. Saito, M. Takahashi, and K. Ito, "Characteristics of cavity slot antenna for body-area networks," IEEE Transactions on Antennas and Propagation, vol. 57, no. 4, pp. 837-843, 2009.

[5] C.-H. Kang, S.-J. Wu, and J.-H. Tarng, "A novel folded UWB antenna for wireless body area network," IEEE Transactions on Antennas and Propagation, vol. 60, no. 2, pp. 1139-1142, 2012.

[6] C.-H. Lin, Z. Li, K. Ito, M. Takahashi, and K. Saito, "Dualmode antenna for on-/off-body communications $(10 \mathrm{MHz} /$ $2.45 \mathrm{GHz}$ )," Electronics Letters, vol. 48, no. 22, pp. 1383-1385, 2012.

[7] C. A. Balanis, Antenna Theory: Analysis and Design, chapter 1, Wiley-Interscience, New York, NY, USA, 3rd edition, 2005.

[8] P. S. Hall, Y. Hao, Y. I. Nechayev et al., "Antennas and propagation for on-body communication systems," IEEE Antennas and Propagation Magazine, vol. 49, no. 3, pp. 41-58, 2007.

[9] K. Kwon, J. Ha, S. Lee, and J. Choi, "Design of a dual-band onbody antenna for a wireless body area network repeater system," International Journal of Antennas and Propagation, vol. 2012, Article ID 350797, 5 pages, 2012.

[10] Y. Hong, J. Tak, and J. Choi, "Dual-band dual-mode patch antenna for on-on-off WBAN applications," Electronics Letters, vol. 50, no. 25, pp. 1895-1896, 2014. 
[11] H. J. Lee, K. L. Ford, and R. J. Langley, "Switchable on/offbody communication at $2.45 \mathrm{GHz}$ using textile microstrip patch antenna on stripline," Electronics Letters, vol. 48, no. 5, pp. 254256, 2012.

[12] J. Tak, S. Woo, J. Kwon, and J. Choi, "Dual-band dual-mode patch antenna for on-/off-body WBAN communications," IEEE Antennas and Wireless Propagation Letters, no. 99, pp. 1-4, 2015.

[13] B. G. Lee and S. Choi, Broadband Wireless Access and Local Networks: Mobile Wimax and Wifi, Artech House, Norwood, Mass, USA, 2008.

[14] G. Held, Building a Wireless Office, CRC Press, Boca Raton, Fla, USA, 2008.

[15] Cisco, "WLAN radio frequency design considerations," in Enterprise Mobility 4.1 Design Guide (OL-14435-01), chapter 3, Cisco Systems, San Jose, Calif, USA, 2007.

[16] D. L. Means and W. Kwok, Evaluating Compliance with FCC Guidelines for Human Exposure to Radiofrequency Electromagnetic Fields, Supplement C (Edition 01-01) to OET Bulletin 65 (Edition 97-01), Federal Communications Commission Office of Engineering \& Technology, 2001.

[17] Ansys High Frequency Structure Simulator (HFSS), ver.15, Ansys Corporation, http://www.ansys.com/Products/Electronics/ANSYS-HFSS.

[18] S. Lee, W. Seo, K. Kwon, and J. Choi, "The study on implementation of a semi-solid flat phantom with equivalent electrical properties to whole human body at MICS and ISM band," The Journal of Korean Institute of Electromagnetic Engineering and Science, vol. 23, no. 1, pp. 101-107, 2012.

[19] Z. Zhang, Antenna Design for Mobile Devices, chapter 4, John Wiley \& Sons, Singapore, 2011.

[20] IEEE, "IEEE standard for safety levels with respect to human exposure to radio frequency electromagnetic fields, $3 \mathrm{KHz}$ to 300 GHz," IEEE Standard C 95, IEEE, 1999.

[21] J. Tak, S. Lee, and J. Choi, "All-textile higher order mode circular patch antenna for on-body to on-body communications," IET Microwaves, Antennas \& Propagation, vol. 9, no. 6, pp. 576-584, 2015. 


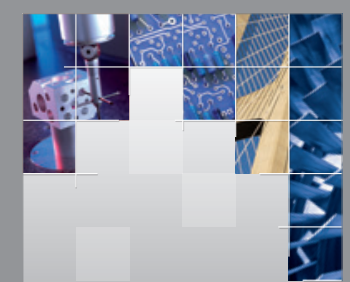

\section{Enfincering}
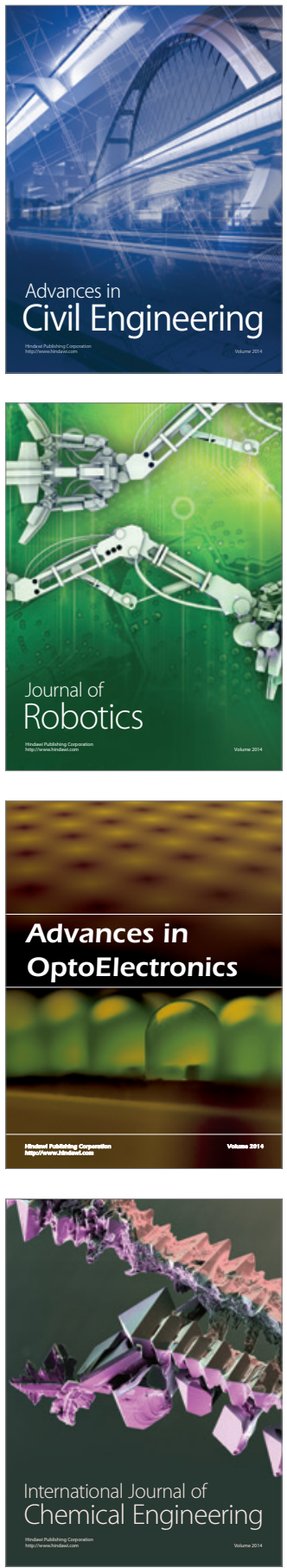

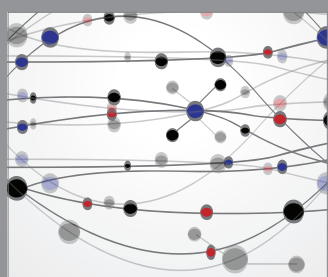

The Scientific World Journal

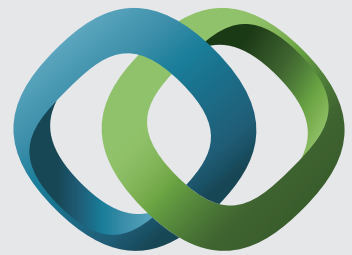

\section{Hindawi}

Submit your manuscripts at

http://www.hindawi.com
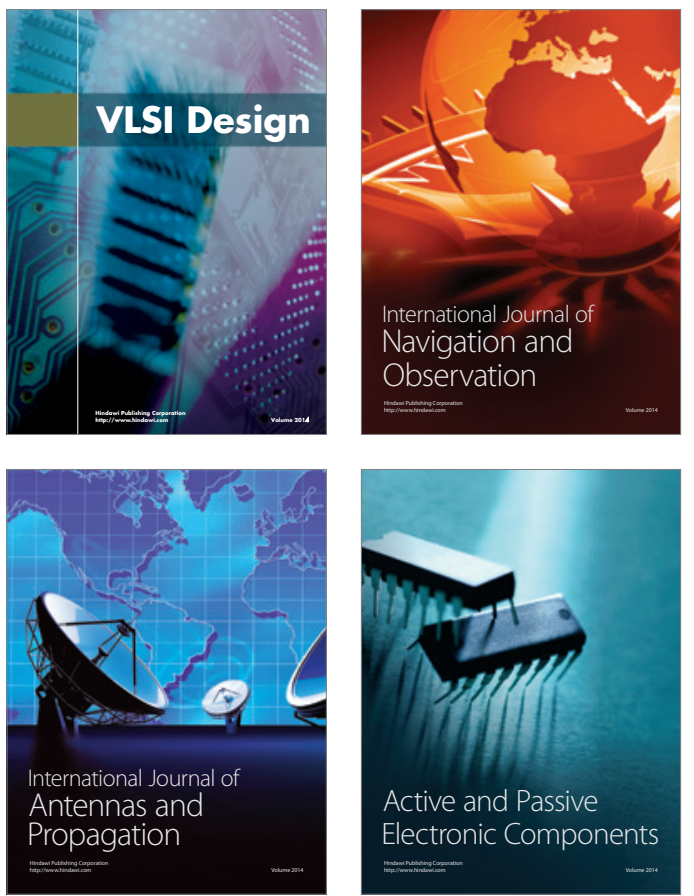
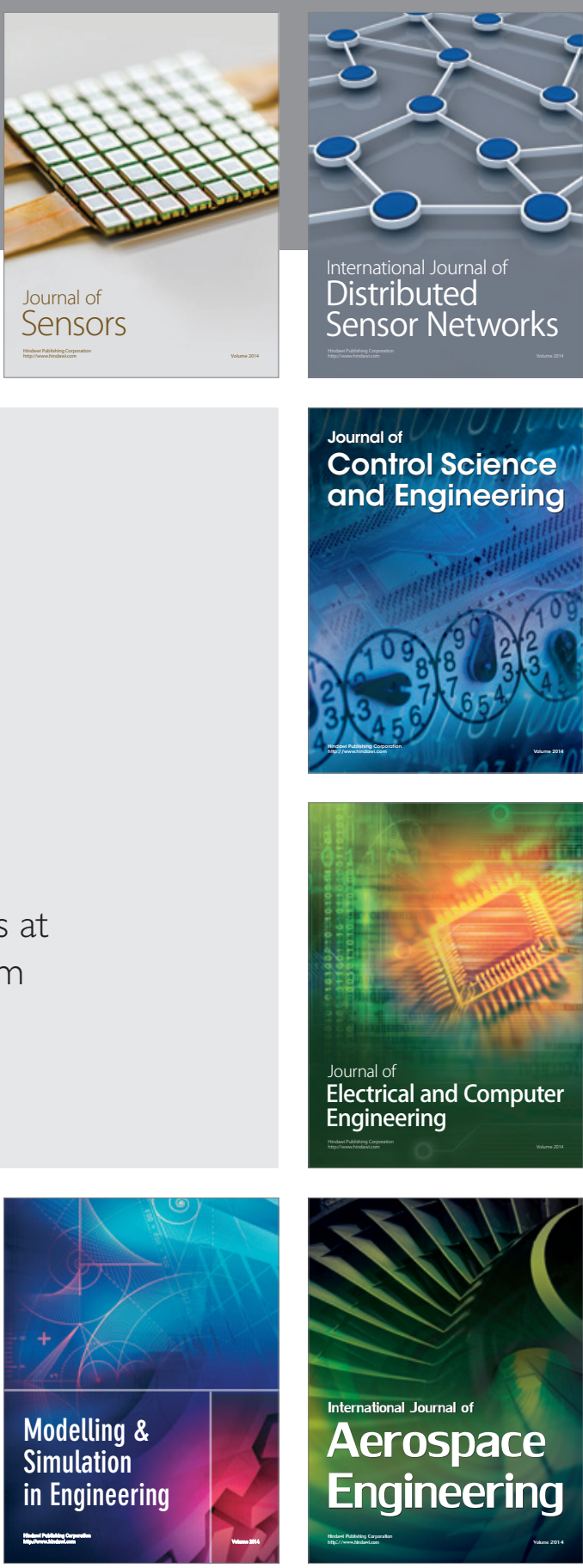

International Journal of

Distributed

Sensor Networks

Journal of

Control Science

and Engineering
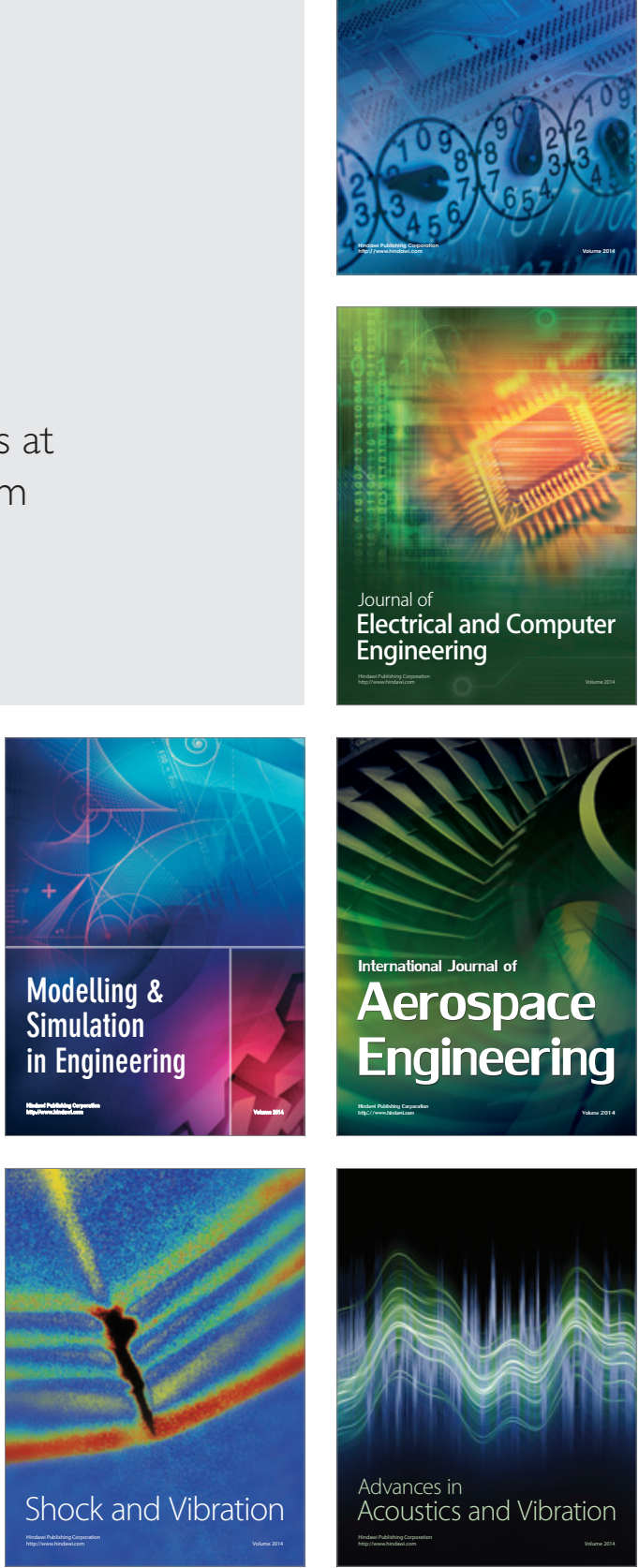